Summary of Duties performed during the Malf-year ending September 29 th.

Number of orders for patients

Visits at patients $\because \ldots \ldots 253$

Ditto by patients at surgery

$\begin{array}{lllll}\text { Mixtures } & \cdots & \cdots & \cdots & \cdots\end{array}$

Poxes of

Boxes of pills... $\quad \ldots \quad \ldots \quad 277$

Liniments $\quad \ldots \quad \ldots \quad \ldots .44$

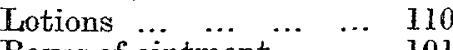

Boxes of ointment... ... 101

Packets of powders $\quad \ldots .961$

\begin{tabular}{llllll} 
Blisters & $\ldots$ & $\ldots$ & $\ldots$ & $\ldots$ & 23 \\
\hline
\end{tabular}

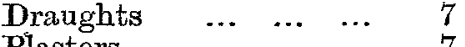

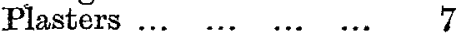

12, Royal-terrace, Weymouth, Sept. 30th, 1855.

Gentuemen, - I beg to lay before you the accompanying copy of a letter which I forwarded yesterday to the Poor-law Board. They will most probably conımunicate with you on the subject. Should they do so, I mast respectfully solicit your aid in support of my views; and if they should not, I trust you will give the subject your earnest consideration; and, in conclusion, beg to quote the words of Judge Willmore in a recent trial ai Yeovil: "If medical officers are screwed down too tight, they are placed in $c$ very painful position-either they must be wanting in their dnties to the poor, or they must be out of pocket, and one would not like to make a man suffer for his honesty. I am glad, therefore, for anything which promotes a liberal tendency in these matters."

I have the honour to be, Gentlemen,

Your obedient servant,

The Board of Guardians, Weymouth Union. RICHARD GRIFFIN.

Poor-law Board, Whitehall, October 2nd, 1855.

SIR, -I am directed by the Poor-law Board to acknowledge the receipt of your letter of the $29 \mathrm{th}$ ultimo, and to inform you that the statements which it coutains will meet with their consideration.

I am, Sir, your obedient servant, Courtenay, Secretary.

Royal-terrace, Weymouth, November 13th, 1855.

MY LORDS AND GENTLEMEN, - I have just received information that the Board of Guardians of the Weymouth Union have again refused to augment my salary, postpouing its consideration until next March. This of course will be officially communicated to you. I need scarcely say the course pursued is so manifestly unjust to me, that I pray your honourable Board will insist upon justice being at once rendered, as you did in the case of a medical officer in the Guildford Union a shor time since, and for which the medical profession thanks you. I will not now go further into details, as my letters of March and September are before you, farther than to say my numbers of fresh orders last week were fourteen, and that in all respects my duties are as laborious as ever; therefore to ask me to work four months and a half longer, when I have already earned twice as much as my whole year's salary, is positively unjust. I have the honour to be, my Lords and Gentlemen, Your obedient servant,

The Poor-law Board. RICHARD GRIFFIN.

Poor-law Board, Whitehall, November 22nd, 1855.

SrR,-I am directed by the Poor-law Board to acknowledge the receipt of your letter of the 13 th instant, respecting your application to the Guardians of the Weymouth Union for an increase in your salary as medical officer for the Weymouth district.

I am directed to inform you that the Board have communicated with the Guardians on the subject, and have received a letter from them, in which they state to the effect, that, having considered your application, they see no sufficient grounds for increasing your solary at present; but that on the expiration of twelve mouths from the date of your appointment they will give the subject their further consideration.

Under these circumstances, and looking to the short period for which you have been the medical officer of the Weymouth district, the Board must decline to interfere further in the matter.

I am, Sir, your obedient servant,
To the Medical Officers of the Unions of Great Britain.

Genthemer, - My correspondence with the Poor law Commissioners and the Board of Guardians of the Weymouth Union is before you. From it you will gather I have had an immense amount of work to perform, and have been most inadequately remunerated. It is true the Board of Guardians have promised to consider the question at the end of the year, but $I$ feel confident they will never give a sufficient compensation. My case is, I know, similar to a vast host of others; indeed, I may say, "ab uno disce omnes." As a body we are shamefully underpaid, and not treated with that consideration due to men of our education. In early life I was for three years one of the honorary surgeons to the Norwich Court of Guardians, and, therefore, well acquainted with the medical working of the Poor Laws, and subsequently held an appointment under the present Poorlaw system, and had to attend a union house four miles from my residence, and several country parishes, the furthest one being nine miles off. For this $I$ was paid after the rate of $£ 50$ per annum, and no extras. At the end of nine months $I$ threw up the appointment with disgust, which I am sure will not surprise you, as the labour was immense, and the pay most paltry. As individuals we are powerless; collectively we may do much. I, therefore, propose that we form a union amongst ourselves, and lay our grievances before Parliament. As some one must take the initiative, I will volunteer to be your honorary secretary to receive communications, in order to set the thing going, until a general committee can be formed, and other arrangements made. I would advise that the surgeons of each union be called together by one of their body, and for them to appoint a local secretary to communicate with me in the first instance, and afterwards the general committee. It will be necessary that subscriptions should be made-say $2 s, 6 d$. each, - and forwarded to me, or be retained by the local secretaries until further steps be taken, as expenses will have to be incurred in printing, drawing up petitions, \&c. In the late case of our naval brethren, Parliament would have been inundated with petitions had not the naval board yielded; we must adopt a similar plan and make ourselves heard. There are upwards of three thousand of us, therefore let us but put forth our strength, and justice will yet be rendered us. We must pray to be removed from the control of the guardians, who are utterly incapable of appreciating our services, and are interested in keeping us under-paid, as most of them are large rate-payers, and request to be placed under a medical board, with medical inspectors, and our salaries entirely paid out of the consolidated fund. A scale of payment should be laid down by which all would receive alike, - say five shillings for each order, - with one shilling extra for each mile the patient resides from the surgeon's residence, with or without extras, as may be agreed on. The amount I merely put hypothetically, in order to draw attention to it. Our salaries might be annually regulated by a calculation of the orders of the previous year, or upon an average of years, as is the case with the clergyman under the Tithe Commutation Act; this would meet a varying population. Vaccination should be placed under the same board, and each case treated as an ordinary order. Regulations should also be framed as to whom are entitled to medical relief. I must own $I$ am inclined to great liberality under this head, as it is desirable that every facility should be given to the poor, who are not actually paupers, obtaining medical assistance.

Many other suggestions will no doubt arise which can be considered in committee.

I have the honour to be, gentlemen,

Your most obedient servant, RICHARD GEIFFIN.

\section{TREATMENT OF MENORRHAGIA BY OXIDE OF SILVER.}

To the Editor of THE LANCET.

SIR,-Although I have long ceased to be a physician-acconcheur, and have occupied myself in the less laborious and less anxious avocations of medicine in general, I cannot resist the inclination to publish in your journal, from which $I$ have derived from time to time much instruction, a case of cure through the agency of that invaluable preparation the oxide of silver, which I myself introdnced to the profession in 1845, and have prescribed more frequently than any other English medical practitioner in cases of long persisting hæmorrhage, diarrhcea, dyspepsia, \&c., and in which my confldence (during

* Practical Remarks on some Exhausting Diseases. Sesond Edition. $*$ Practical $R$
Churchill, 1845. 
a steady trial on a sufficiently large scale, of fourteen years' duration, publicly and privatcly) is stronger than ever it was. I subjoin the gratifying report of my friend, Mr. Walter Jones. I am, Sir, your obliged and faithful servant, Lower Brook-street, Dee. $185 \tilde{3}$. JAMES EYRE, M.D.

I have great pleasure in forwarding to you the notes of the case I mentioned to you a short time ago. The patient, Mrs. W. W--_, aged twenty-eight years, delicate looking, was the mother of one child, aged five years, and had a subsequent miscarriage but did well after it, about the beginning of January, 1854, was taken with severe menorrhagia, for which, on the 10th January, 1854, the ergot, combined with tonics (auinime, \&c.), was given twice a-day, and continued till the 18th January without much benefit, when the sulphate of iron was combined with the ergot and persevered in for a week (till the 24th January) without her deriving any benefit, at which time sulphuric and gallic acid, with a bitter, were administered, also a solution of alum and sulphate of zinc, to be used as an injection thrice daily. These remedies were continued till the 5th February, without the slightest relief, the patient getting very low in consequence of the continued drain going on. Dr. - was called in for consultation, and prescribed full doses of the tincture ferri sesquichloride three times a day, and a pill every night of superacetate of lead one grain and a half, and pulv. opii, half a grain. The hæmorrhage still continuing to a serious extent, with frequent faintness, cold was applied to the vulva, \&c., \&c., bandaging, \&c. On the 12th February she took the tincture ferri and quinine, with some secale, and under its influence she slightly improved, till the 16th, on which day her medicine was changed to spts. æth. nit., tincture cinnamon co., and tincture calumba, and continued till the 18th, on which day she became much worse; gallic acid was given in twelve-grain doses, and pil. saponis c. opio, five grains, $\mathbf{0 . n}$. ; this was continued with but slight benefit till the 24th February, when $I$ gave her one-drachm doses of the bitartrate of potash three times a day. She derived more benefit from this remedy than anything she had yet taken, and it was continued till the 18 th March (which was nearly a month), on which day the hremorrhage returned to a most alarming extent; the fainting coming on at frequent intervals, and on the slightest movement, and, indeed, at one time, life seemed to be all but extinct. Stimulants of various kinds were administered freely as the only chance of saving her. While in this fearful state, Dr. - was sent for. He prescribed the following, R. Argent. oxid. one grain and a half, ext. tarax. pulv. tragac. co., of each six grains, div. in pilulæ six, capiat $i$. ter die. After the few first doses there was a marked change for the better, and from that time there was daily improvement till the middle of April (taking her pills daily), when, very soon after, she was able to go to the sea-side. She has since been confined (on the 19th June, 1855) of a fine living boy, which she is suckling at the present time, and has never had a repetition of the discharge, and is now in good health.

During her confinement I was rather apprehensive of hæmorxhage coming on, but fortunately everything passed off very well. The above case plainly shows the valuable properties of the oxide of silver in this class of cases. All the best remedies known were tried with but little benefit, and I feel confident that had it not been for this preparation acting so beneficially, the patient's life would, in a few hours, have been lost. It deserves a well-spread notoriety, and, doubtless, many cases prove fatal from the want of knowledge respecting the properties of the oxide of silver.

With feelings of high esteem I remain, dear Sir James, Yours sincerely,

Fetter-lane, Nov. 1855. WALTER JONES.

\section{PRIVATE PRACTYCE VERSUS UNION PRACTICE}

To the Editor of THE LANCET.

SrR, - In THE LANCET for November 10 th you approve of the occasional publication of the duties and remuneration of union surgeons. Perhaps it would prove useful to compare private practice with union practice. I am a surgeon practising in a large town within forty miles of London; the inhabitants are very poor, and the better classes unwilling to pay liberally. am now in the fifth year of practice. As I keep a register of cases, and an advice-book, I am able to inform you exactly of the number of professional acts performed by me in the year. I charge exclusively for advice, theretore I omit the considera tion of medicines. Under the term professional act $I$ include visits, advice at my own house, operations, vaccination, and midwifery.

My professional acts for my fourth year, 1854-55, amounted to 5101 . I attended 658 cases of illness occurring in 469 individuals. The number of midwifery cases amounted to nine. The cash received was the sum of $£ 1730 s .6 c$. Thus the receipts amounted to $7 s$. $\frac{4 \frac{1}{16}}{1} d$. for each individual, or $5 s .3 \frac{1}{8} d$. for each case of illness. For each professional act I received $8 \frac{1}{7}$ d. My daily average of acts was 13.97 in number.

On comparing this summary with that furnished by the union surgeon, whose letter appeared in your pages, it will be seen that a young surgeon in private practice of a very poor description is far better remunerated than a union surgeon. The union surgeon's summary is as follows, omitting medicines :--For one quarter, 130 patients (individuals or cases of illness?) and 978 professional acts, the remuneration was \&8 15s. This would furnish the following numbers for one year:- 540 patients, 3912 acts, $£ 35$. Thus the remuneration would be $2 \frac{1}{7} d$. for each act (exclusive of medicine); or $1 s .3 \frac{11}{20} d$. for each patient.

I take the present opportunity to arge upon the consideration of the union surgeons the necessity of keeping an exact account of their professional acts, with the view of obtaining redress for the grievances under which they suffer. I advise the union surgeons to elect a committee, so as to press forward the reform that is so urgently needed. The matter must be agitated in Parliament, steadily and without dis couragement. The union surgeons' case is monstrous. The salaries are miserable as salaries, altogether omitting the consideration of the supply of medicine.

What is required is a certain remuneration according to the area of acres, and the number and social condition of the population; a house, a horse and man-servant, and medicines, all free. superintendence by medical inspectors; payment out of the Consolidated Fund; permanency of office; and pensions.

The Poor-law service should be assimilated to the other branches of the public service. If it were reformed it would constitute an excellent machinery for sanitary purposes. 3000 reports, every quarter, on the existence of epidemics throughout the length and breadth of the land, by overseers practising amongst that portion of the people most liable to epidemics, would powerfully advance the canse of Hygiène.

It is clear that every union surgeon should, from this time forth, keep an exact register of his professional acts, together with extent of country travelled over, so that the committee may have facts to work with.

Nov. 1855

I am, Sir, your obedient servant,

F. J. B.

\section{THE CASE OF DR. MURPHY, OF CORK.} To the Editor of THE LANCET.

Sir, - The LANCET was one of the first periodicals which advocated " justice to the members of the profession," and presuming that you must have had reports of the proceedings of the medical practitioners of the county and city of Cork, who came forward as one man, to resist oppression aimed at a medical officer of the Cork Dispensary, through his dismissal by the Poor-law Commissioners' " sealed order," which issued, and for a time took effect. I have felt surprised that you did not notice the circumstance in your journal, which circulates so widely throughout Ireland. However, it may not be too late to show the profession at large throughout the United Kingdom what may and can be done by unanimity; and, therefore, if you will kindly permit me, I will as succinctly as possible detail the cause and effect of the movement in Cork.

In July last, a medical officer of the dispensary was threatened with arrest for clebt, and to avoid the arrest until he could provide the amount due, with the usual formal application to the secretary of the institution, obtained two or three days' leave of absence, and named a medical man to perform his duties. Within the limits of his leave he was arrested, and again wrote in accordance with the Poor-law Commis sioners' Rules, asking for an extension of leave, but of course naturally not stating his cause of absence. Under the Rules, or "Articles" as they are called, the secretary is required, on receipt of such application for leave of absence from a medical officer, to summon an "extraordinary meeting" of the committee of the dispensary to approve or dissent, both as to the request and the locum tenens; but, in this case, no such extraordinary meeting was convened, and five (out of sixty-six) members of the committee, who met on the "ordinary" busi- 